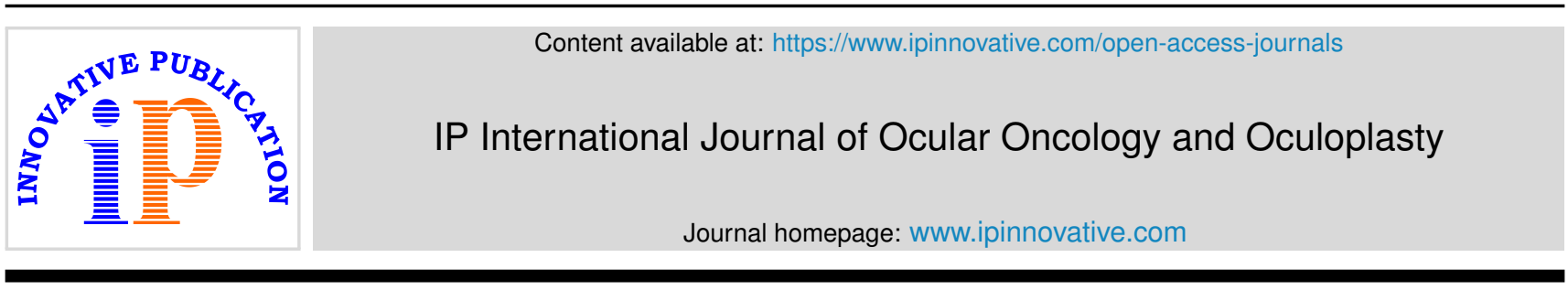

\title{
Editorial
}

\section{Clinical spectrum and profile of circumstantial stress induced ocular trauma in complete COVID lockdown attending tertiary eye care services}

\author{
Manu Saini' ${ }^{1 *}$, Arun K Jain', Chintan Malhotra', Kulbhushan Saini' ${ }^{2}$ \\ ${ }^{1}$ Dept. of Ophthalmology, Post Graduate Institute of Medical Education \& Research, Chandigarh, India \\ ${ }^{2}$ Dept. of Anesthesia, Post Graduate Institute of Medical Education \& Research, Chandigarh, India
}

A R T I C L E I N F O

Article history:

Received 10-06-2020

Accepted 10-07-2020

Available online 03-09-2020
(C) 2020 Published by Innovative Publication. This is an open access article under the CC BY-NC license (https://creativecommons.org/licenses/by-nc/4.0/)

\section{To the Editor}

Our data provides the current pattern of clinical spectrum and profile of ocular trauma, attending tertiary emergency eye care services in complete COVID lockdown period. About $31.14 \%$ (19/61) of all cases presenting to ophthalmic emergency (mean age $25.94 \pm 14.95$ and male: female ratio 16:3) in the enforced complete lockdown period from 25 March to 30 April 2020 were of circumstantial ocular trauma shown in Table 1 and 52.63\% (10/19) of them required surgery due to severe ocular injury. Open globe: Closed globe injuries were $21.05 \%$ : $68.42 \%$ respectively with $10.52 \%$ cases had lid lacerations. Clinical spectrum of circumstantial ocular injury inflicted in COVID lockdown phase is graphically represented in Figure 1.

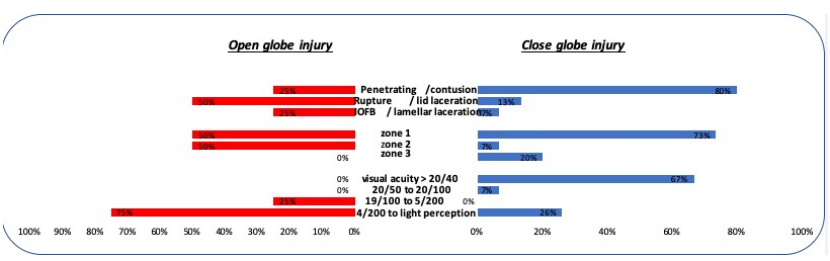

Fig. 1: Comparison of open globe versus close globe injuries sustained is represented as tornado graphically, in complete COVID lockdown attending tertiary eye care services.

\footnotetext{
* Corresponding author.

E-mail address: manusaini.1024@gmail.com (M. Saini).
}

Table 1: Clinical profile of ocular trauma presented in Complete COVID lockdown

\begin{tabular}{lc}
\hline Mode of injury & No of patients \\
Fall on ground & 1 \\
TV Remote & 2 \\
Dish bowl & 1 \\
Toy & 1 \\
Broom stick & 4 \\
Door knob & 1 \\
Bed corner & 1 \\
During Mopping & 2 \\
Ball & 2 \\
Hand nail & 2 \\
During exercise & 1 \\
Book cover & 1 \\
\hline
\end{tabular}

\section{Discussion}

Most of the patients who sought health care facilities were adult males and had history of watching COVID related information on social media, news for more than 6 hours in a day with added anxiety and restlessness. More than half of the ocular trauma were of severe nature, required surgical repair resulted from compromised biological, cognitive and behavioral response under influence of constant threat, social withdrawal in lock down phase, suggesting COVID related stress behave as an impediment to ponder the 
performance of daily activity and level of attention.

Injuries sustained to the eye was due to composite mechanism of mechanical and non -mechanical factors attributed to the extra ordinary stressful situation, feeling of physical and emotional drained and shattered sense of security to acknowledge potential source of injury, made them fragile and vulnerable to the trauma. This is aggravated by round-the-clock news and social media coverage on COVID and its related information that implies constant bombardment with horrific images of tragedy, suffering, and loss almost the instant they occurred anywhere in the world. Repeated exposure of these utterance overwhelmed nervous system and created traumatic stress just as if they experienced the event first-hand. ${ }^{1}$ It's in fact, continuous stress and elevated cortisol levels that negatively impact the eye and brain harmony due to autonomous nervous system imbalance and vascular dysregulation as proposed by Bernhard et al. ${ }^{2}$ Attenuating this adrenaline level and releasing endorphins by doing exercise can actually help to repair our nervous system, ${ }^{3}$ fever overthinking and cope up COVID stress.

Hence, we realized that COVID stress (and certain personality dispositions) is the appreciated factor exacerbating ocular trauma in least anticipated circumstances of injury during COVID lockdown phase.

\section{Source of Finding}

None.

\section{Conflict of Interest}

None.

\section{References}

1. Smith M, Robinson L, Segal J. How to Cope with Traumatic Events like Coronavirus. Help guide; 2020.

2. Sabel BA, Wang J, Cárdenas-Morales L, Faiq M, Heim C. Mental stress as consequence and cause of vision loss: the dawn of psychosomatic ophthalmology for preventive and personalized medicine. EPMA J. 2018;9(2):133-60.

3. Robinson L, Smith M, Segal J. Emotional and Psychological Trauma. Help guide; 2020.

\section{Author biography}

Manu Saini Assistant Professor

Arun K Jain Professor and Head of Unit

Chintan Malhotra Additional Professor

Kulbhushan Saini Assistant Professor

Cite this article: Saini M, Jain AK, Malhotra C, Saini K. Clinical spectrum and profile of circumstantial stress induced ocular trauma in complete COVID lockdown attending tertiary eye care services. IP Int J Ocul Oncol Oculoplasty 2020;6(3):155-156. 